\title{
Diagnosi di carcinoma papillare tiroideo (variante cistica) a seguito di comparsa di tumefazione laterocervicale
}

\author{
Paola Magnoni $^{1}$ • Pasquale De Nittis ${ }^{1}$
}

Pubblicato online: 21 luglio 2015

C Springer International Publishing AG 2015

In data 7 giugno 2012 si presenta a visita chirurgica presso il nostro istituto un paziente maschio di 42 anni per dolenzia al collo a sinistra e tumefazione clinicamente apprezzabile da circa 1 mese. Un'ecografia eseguita presso altra sede evidenziava "voluminosa formazione cistica transonica del lobo tiroideo sinistro con depositi fibrinici basali" e "al terzo mediosuperiore della metà sinistra del collo dietro allo STCM formazione cistica di $16 \mathrm{~mm}$ ". Gli esami sierologici portati in visione mostravano una normale funzionalità tiroidea, calcitonina nella norma e negatività per la presenza degli anticorpi anti-tireoglobulina e anti-tireoperossidasi. Il chirurgo concludeva per "possibile cisti del margine posteriore dello sternocleoidomastoideo sinistro" e consigliava ripetizione dell'ecografia ed eventuale agoaspirato.

All'ecografia del 13 giugno 2012, eseguita presso il nostro Istituto, si evidenziava la presenza di adenopatia in gran parte cistica delle dimensioni di $1,5 \mathrm{~cm}$ in sede laterocervicale sinistra riccamente vascolarizzata (Fig. 1a) e di voluminoso nodulo in gran parte cistico nel lobo tiroideo di sinistra (Fig. 1b). Il paziente veniva quindi sottoposto a duplice agoaspirato. L'esame citologico mostrava la presenza di carcinoma papillare con interessamento della formazione linfonodale laterocervicale sinistra.

Il paziente veniva sottoposto a tiroidectomia totale con svuotamento linfonodale LC sinistro e l'esame istologico poneva diagnosi di "carcinoma papillare bifocalecon estensione ai tessuti molli peritiroidei; metastasi ad un linfonodo di III livello e a due di IV livello". Il paziente veniva quindi sottoposto a terapia radiometabolica con ${ }^{131} \mathrm{I}$ ed è attualmente in follow-up.

P. Magnoni

paola.magnoni@humanitas.it

1 U.O. Ecografia, Humanitas Research Hospital, Via Manzoni 25, 20089 Rozzano, Milano, Italia
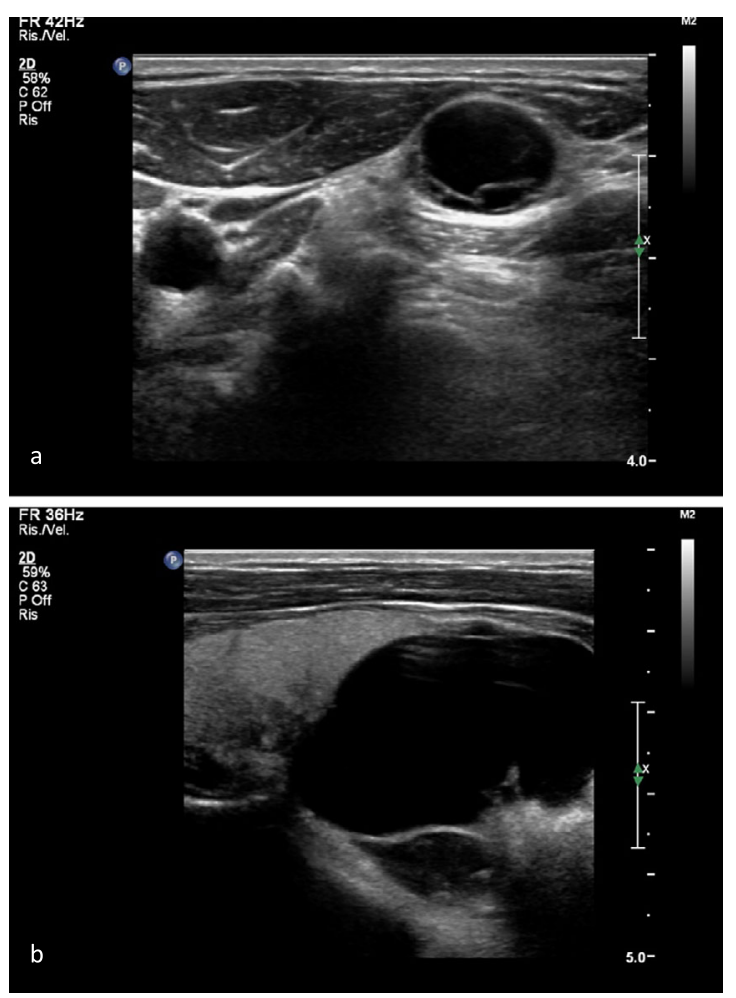

Fig. 1 Ecografia tiroidea: presenza di adenopatia in gran parte cistica delle dimensioni di $1,5 \mathrm{~cm}$ in sede laterocervicale sinistra riccamente vascolarizzata (a). Concomita voluminoso nodulo in gran parte cistico nel lobo tiroideo di sinistra con alcuni setti interni e grossolane calcificazioni nella parte più profonda (b). Sempre a sinistra, piccolo nodulo misto di $6 \mathrm{~mm}$

Conflitto di interesse Gli autori Paola Magnoni e Pasquale De Nittis dichiarano di non avere conflitti di interesse.

Consenso informato Lo studio presentato in questo articolo non ha richiesto sperimentazione umana.

Studi sugli animali Gli autori di questo articolo non hanno eseguito studi sugli animali. 